\title{
Finite element structural redesign by large admissible perturbations
}

\author{
M.M. Bernitsas, E. Beyko, C.W. Rim \& B. Alzahabi \\ Department of Naval Architecture and Marine Engineering. The University of Michigan, Ann Arbor, Michigan 48109-2145, USA
}

(Received 22 October 1991; accepted 27 January 1992)

\begin{abstract}
In structural redesign, two structural states are involved: the baseline (known) state S1 with unacceptable performance, and the objective (unknown) state S2 with given performance specifications. The difference between the two states in design variables and performance may be as high as $100 \%$ or more depending on the scale of the structure and the design problem considered. A perturbation approach to redesign (PAR) is presented to relate any two structural states $\mathrm{Si}$ and $\mathrm{S} 2$ that are modeled by the same finite element model but represented by different values of the design variables. General perturbation equations are derived expressing implicitly the natural frequencies, dynamic modes, static deflections, static stresses, Euler buckling loads and buckling modes of the objective state $\mathbf{S} 2$ in terms of its performance specifications, and only state $\mathbf{S 1}$ data and FEA results. Large admissible perturbations (LEAP) algorithms are implemented in code RESTRUCT to define the objective state S2 incrementally without trial and error by postprocessing FEA results of state S1 with no additional FEAs. Systematic numerical applications in redesign of a 10-element 48-d.o.f. beam, a 104-element 192-d.o.f. offshore tower, a 64-element, 216-d.o.f. plate, and a 144-element 896-d.o.f. cylindrical shell show the accuracy, efficiency, and potential of PAR to find an objective state that may differ $100 \%$ or more from the baseline design.
\end{abstract}

\begin{abstract}
NOTATION
$c_{i j}$

Admixture coefficient for participation of the $j$ th mode to changes in the $i$ th mode

d.o.f.(s) Degree(s) of freedom

$E \quad$ Young's modulus

FE Finite element

FEA Finite element analysis

FEM Finite element method

$g_{k}(\mathbf{u})$

$[k],\lfloor K\rceil$

$\left[k_{e}\right]$

$K_{i}$

LEAP

$[m] \cdot[M]$

$\left[m_{e}\right]$ Global limit state function Global and generalized stiffness matrices Stiffness matrix of element or group of elements related to property $e$ $i$ th component of $[K]$ Large admissible perturbations Global and generalized mass matrices Mass matrix of element or group of elements related to property $e$
\end{abstract}

$M_{i}$

Applied Ocean Research 0141-1187/92/\$05.00 (C) 1992 Elsevier Science Publishers Ltd.

\begin{tabular}{|c|c|}
\hline$M_{i}$ & $i$ th component of $[M]$ \\
\hline$n$ & $\begin{array}{l}\text { Number of degrees of freedom in FE } \\
\text { model }\end{array}$ \\
\hline$n_{\mathrm{a}}$ & Number of admissibility constraints \\
\hline$n_{\mathrm{r}}$ & $\begin{array}{l}\text { Number of extracted structural modes } \\
\text { used in RESTRUCT }\end{array}$ \\
\hline$n_{u}, n_{\Omega}, n_{\dot{\phi}}$ & $\begin{array}{l}\text { Number of displacement, frequency, and } \\
\text { dynamic modal node failure criteria }\end{array}$ \\
\hline$n_{\sigma}, n_{\mathrm{b}}, n_{\sigma \mathrm{b}}$ & $\begin{array}{l}\text { Number of stress, buckling loads, and } \\
\text { buckling modal node failure criteria }\end{array}$ \\
\hline$N$ & $\begin{array}{l}\text { Number of increments in incremental } \\
\text { algorithm }\end{array}$ \\
\hline$p \cdot q$ & $\begin{array}{l}\text { Number of rigidity and load random } \\
\text { variables, respectively }\end{array}$ \\
\hline$P_{\mathrm{cr}_{i}}, P_{i}$ & ith critical Euler buckling load \\
\hline$P_{\mathrm{F}}$ & Probability of failure \\
\hline PAR & Perturbation approach to reliability \\
\hline RESTRUCT & Program for redesign of structures \\
\hline SFEM & Stochastic FEM \\
\hline SSR & Structural systems reliability \\
\hline $\mathrm{S} 1, \mathrm{~S} 2$ & $\begin{array}{l}\text { Initial and other structural state, respec- } \\
\text { tively }\end{array}$ \\
\hline
\end{tabular}


$\mathrm{S} 2_{k} . \mathrm{S} 2_{k}^{*} \quad$ Limit state and design point. respectively. on limit state $k$

$\{u\}, \mathbf{u} \quad$ Nodal static displacement vector

$\mathbf{u}_{k}^{*}, \mathbf{u}_{k l}^{*} \quad$ Individual and joint design point, respectively

$\alpha_{e} \quad$ Fractional change to element or group property $e$

$a_{e^{*}}, \alpha_{e}^{-} \quad$ Lpper and lower bounds of $\alpha_{e}$

$3_{k} \quad$ Hasover and Lind reliability index for $k$ th design point

$\delta \quad$ Prefix denoting incremental change

$\Delta \quad$ Prefix denoting total change

$\{\sigma\} \quad$ Equivalent stress nodal vector

$[\phi] \quad$ Matrix of mode shape vectors

$\varphi_{k i} \quad k$ th degree of freedom of $i$ th mode shape

$\{\Psi\}_{i},\left\{\Psi_{\mathrm{b}}\right\}_{i} \quad$ ith dynamic and buckling mode, respectively

$\omega_{i}$ $i$ th natural frequency

Indices and special symbols

e.f Index for rigidity and load random variables, respectively

1 Index denoting quantity in increment $1.1=1.2 \ldots . . N$ ()$^{\prime}$

Indicates diagonal matrix

Prime denotes structural property of state S2

\section{INTRODUCTION}

Several problems in analysis, design, and modification of a structure or a structural design can be stated as redesign problems. These can be expressed as two-state problems involving the baseline state $S I$ and the objective state $\mathrm{S} 2 . \mathrm{S} 1$ is known and has been modeled and analyzed by FEM. In the event that the performance of state $\mathbf{S} 1$ is unacceptable, the objective state $\mathbf{S} 2$ must be defined to satisfy performance specifications. The perturbation approach to redesign (PAR) developed in this work can relate any two structural states that can be modeled and analyzed by the same FE model. PAR has the potential to perform redesign in the sense of resizing. reshaping, and reconfiguration to satisfy any performance requirements that can be predicted by FEA including modal dynamics, static deflections and stresses, and global buckling. LEAP (large admissible perturbations) algorithms implemented in code RESTRUCT

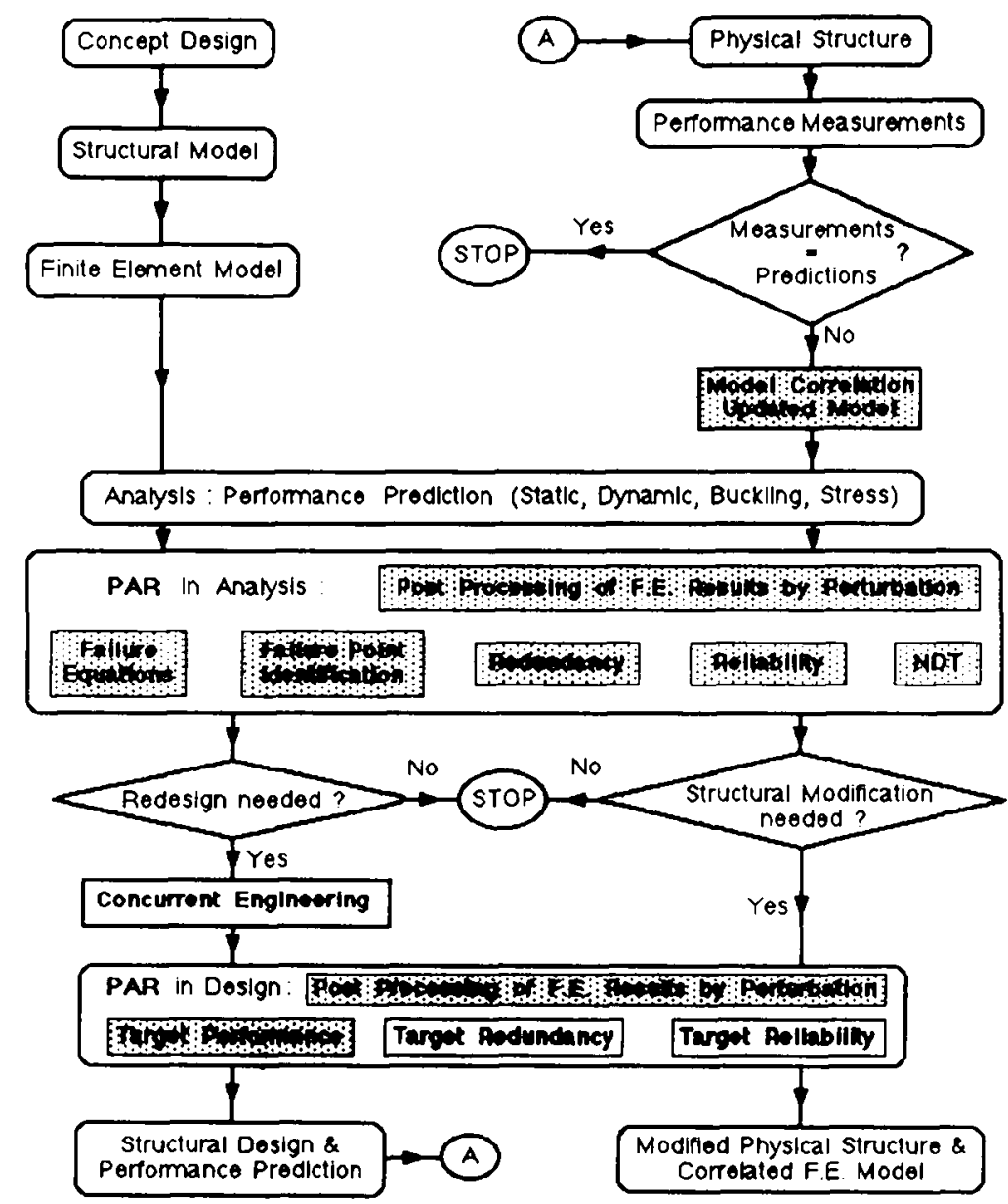

Fig. 1. Structural analysis and design problems solved by PAR (rectangular blocks indicate problems that can be solved by LEAP theory; shaded blocks indicate problems already solved in some form). 
(redesign of structures) ${ }^{l}$ can presently handle resizing for natural frequencies, mode shapes and static deflections.

Figure 1 shows several two-state problems that appear in the analysis-design-redesign process following a basic FE analysis. In analysis, the following two-state problems are encountered: (P1) model correlation, $^{2}$ (P2) derivation of global failure equations, ${ }^{3,4}$ (P3) failure point identification, ${ }^{4}$ (P4) redundancy, ${ }^{4}$ (P5) reliability ${ }^{5}$ (P6) nondestructive testing. ${ }^{6}$ In design, the following two-state problems are encountered: (P7) redesign for target performance, ${ }^{3,6-11}$ (P8) redesign for target redundancy and (P9) redesign for target reliability.

LEAP theory was developed during the past seven years from the linear perturbation techniques introduced by Stetson in $1975^{10,11}$ and modified by Sandström and Anderson. ${ }^{6}$ They redesigned a structure for both natural frequency and mode shape objectives but allowed only small differences between the baseline and objective states. In this respect, linear perturbation methods are equivalent to design sensitivity methods. Nonlinear perturbation methods ${ }^{8,9}$ allow for large differences between the two states. The objective state is found by postprocessing data of the baseline structure only, using an incremental prediction correction scheme. ${ }^{3}$ Presently, research efforts are directed towards two goals. The first is to redesign larger scale structures as far away from the baseline structure as possible before a second FEA is needed. Large admissible perturbations ${ }^{3}$ updating only cognate modes $^{7}$ in an incremental process are used towards this end. Substructuring is also investigated for this purpose, as well as for reshaping and reconfiguration. The second goal is to implement more and different objectives and derive the corresponding general perturbation equations. LEAP algorithms are under development for static stress, global buckling load, and buckling mode objectives.

In this paper, the general problem of redesign - in the sense of resizing - is formulated for modal dynamics (frequency and mode), static deflection, static stresses, and Euler buckling (load and mode) objectives by developing PAR. This formulation is presented in Section 2. Several two-state problems mentioned above are stated as redesign problems in Section 2.1. The perturbation approach to redesign is presented in Section 2.2 and LEAP theory for development of solution algorithms is summarized in Section 2.3. Many numerical applications using four different structures are presented in Section 3 to assess the potential and limitations of PAR and the present status of code RESTRUCT.

\section{REDESIGN BY LARGE ADMISSIBLE PERTURBATIONS}

A simple modeling-analysis-design-redesign process for structures using FEM is shown in Fig. 1. Rectangular blocks indicate two-state problems which can be formulated as redesign problems using PAR and solved efficiently by a LEAP algorithm. Shaded blocks indicate problems already solved in some form by code RESTRUCT. Some of those problems are discussed below.

\subsection{Redesign and other two-state problems}

The classical structural redesign problem appears in Fig. 1 after analyzing either the original or the correlated (calibrated) FE model. Undesirable responses - such as a natural frequency in the range of wave excitation, a dynamic mode with high amplitudes near the free surface where wave and current loads are maximum, or high stresses and deflections - make redesign mandatory. The performance specifications of the objective design are desirable values of those response particulars.

After placing a structure in service, tests are performed to measure its performance and compare it to FEM predictions. In the modeling process, simplifying assumptions, uncertainty, and ignorance result in discrepancies between measurements and predictions particularly for marine structures which have large manufacturing tolerances. The process of finding a FE model of a physical structure that will correctly predict measured structural response is called model correlation. The initial FE model is the known state S1. The objective state $\mathrm{S} 2$ represents the unknown correlated FE model. The perturbation approach to redesign presented in the following section preserves element connectivity and changes geometric properties so that the correlated model represents a real structure. ${ }^{7}$ That is, PAR does not change simply numbers in the mass and stiffness matrices; PAR can also solve the problem of model correlation for geometry dependent hydrodynamic load. $^{2}$

The problem of failure point identification can also be formulated by PAR and solved by a LEAP algorithm. $S 1$ represents the initial structural state and $S 2$ the unknown failure point (design point in reliability terminology) on a limit surface. ${ }^{12.1 \frac{1}{3}}$. The advantage of PAR is that it can provide an implicit expression for a global failure criterion by relating state $\mathrm{S} 2$ to $\mathrm{S} 1 .^{14}$

Related is the problem of reserve and residual redundancy. In the literature, several different aspects of redundancy are presented as definitions depending on the type of structure and analysis performed. ${ }^{15-17}$ PAR remedies this lack of an invariant and consistent redundancy definition by introducing a redundancy injective mapping ${ }^{4}$ defining the difference between the initial intact or damaged structure and the design point.

Finally, a new methodology for reliability analysis and design of large scale structures is under development based on PAR. ${ }^{5,14}$ The perturbation approach to 
reliability provides an alternative to the systems approach $^{15.18 .19}$ and the stochastic FEM $^{20.21}$ which are the two most popular methods in structural reliability. PAR makes possible the introduction of advanced structural analysis in the reliability computations without simplifying the structure. PAR also allows randomness in geometry, material, and load. There is no limitation to the number of random variables used and the random load need not be applied in a specific pattern until structural failure. The reliability analysis problem is a two-state problem where $\mathrm{S} !$ is the initial structure and $S 2$ the design point.

PAR can also address the very difficult problems of target redundancy and target reliability design. $\mathrm{S} 1$ is the initial structural design of inadequate redundancy or reliability and $\mathrm{S} 2$ is the objective structure of specified redundancy or reliability. ${ }^{5}$ These are difficult design problems because redundancy and reliability are not computed directly by FEM. PAR can solve these problems because of the introduction of an injective mapping relating $\mathrm{S} 1$ to $\mathrm{S} 2 .^{4}$

\subsection{Perturbation approach to redesign (PAR)}

The PAR methodology can formulate the above twostate problems as explained in this section. PAR has five major steps, as follows.

\subsubsection{Step 1}

A structure (SI) is modeled and analyzed by a general purpose FE code; MSC/NASTRAN is used in the present work. So far, four types of analysis have been considered in PAR and the governing equations follow. For modal dynamics the free vibration equations for $\mathrm{S} 1$ are:

$$
\left([k]-\omega_{i}^{2}[m]\right)\{\psi\}_{i}=\{0\} \quad \text { for } i=1,2, \ldots, n
$$

where the $n$ eigenvalues $\omega_{i}, i=1,2, \ldots, n$ satisfy equation det $\left([k]-\omega_{i}^{2}[m]\right)=0$. In eqn (1), damping may be included only in Rayleigh's form and added mass is included in $[m]$. For the static deflections and stresses of $\mathrm{SI}$ we have:

$$
\begin{aligned}
& {[k]\{u\}=\{f\}} \\
& \{\sigma\}=[S][k]^{-1}\{f\} \\
& {[S]=[G][D][N]}
\end{aligned}
$$

where $[G],[D],[N]$ are the stress-strain, strain-displacement, and shape function matrices. The governing equation for global buckling in finite elements is:

$$
\left(\left[k_{0}\right]+\left[k_{\sigma}\right]\right)\left\{\psi_{\mathrm{b}}\right\}=\{0\}
$$

where $\left\{k_{0}\right\}$ and $\left[k_{\sigma}\right\}$ are the small displacement and initial geometric stiffness matrices.

\subsubsection{Step 2}

The following perturbation relations are introduced relating states $\mathrm{S} 2$ to $\mathrm{S} 1$ :

$$
\begin{aligned}
& {\left[k^{\prime}\right]=[k]+[\Delta k]} \\
& {\left[m^{\prime}\right]=[m]+[\Delta m]} \\
& {\left[\omega^{\prime 2}\right]=\left[\omega^{2}\right]+\left[\Delta\left(\omega^{2}\right)\right]} \\
& {\left[\phi^{\prime}\right]=[\phi]+[\Delta \phi]}
\end{aligned}
$$

where unprimed and primed symbols refer to the baseline (S1) and the objective state $S 2$, respectively. Prefix $\Delta$ indicates difference between counterpart quantities of states $\mathrm{S} 1$ and $\mathrm{S} 2 . \quad[\phi]=\left\{\{\varphi\}_{1}\right.$. $\left.\{v\}_{2}, \ldots,\{v\}_{n}\right]$ is the matrix of eigenvectors of $\mathrm{SI}$ and $\left[\omega^{2}\right]$ is the diagonal matrix of the corresponding eigenvalues. Perturbation relations pertaining to eqns (2) and (3) are:

$$
\begin{aligned}
& \left\{u^{\prime}\right\}=\{u\}+\{\Delta u\} \\
& \left\{f^{\prime}\right\}=\{f\}+\{\Delta f\} \\
& \left\{\sigma^{\prime}\right\}=\{\sigma\}+\{\Delta \sigma\} \\
& {\left[S^{\prime}\right]=[S]+[\Delta S]}
\end{aligned}
$$

For the global buckling eigenvalue problem we have:

$$
\begin{aligned}
& {\left[k_{0}^{\prime}\right]=\left[k_{0}\right]+\left[\Delta k_{0}\right]} \\
& {\left[k_{\sigma}^{\prime}\right]=\left[k_{\sigma}\right]+\left[\Delta k_{\sigma}\right]} \\
& {\left[P_{\mathrm{cr}}^{\prime}\right]=\left[P_{\mathrm{cr}}\right]+\left[\Delta P_{\mathrm{cr}}\right]} \\
& {\left[\dot{\phi}_{\mathrm{b}}^{\prime}\right]=\left[\phi_{\mathrm{b}}\right]+\left[\Delta \dot{\phi}_{\mathrm{b}}\right]}
\end{aligned}
$$

Further, in step 2, desirable values of some response particulars of $\mathbf{S 2}$, such as natural frequencies, static deflections and mode shapes, are specified. An incomplete set of mode shapes may be used and only some degrees of freedom may be defined in each mode.

\subsubsection{Step 3}

The differences in structural properties between $\mathrm{S} I$ and $\mathrm{S} 2$ are expressed in terms of the fractional changes $\alpha_{e}, e=1,2, \ldots, p$ of $p$ properties of elements or groups of elements as:

$$
\begin{aligned}
& {[\Delta k]=\sum_{e=1}^{p}\left[\Delta k_{e}\right]=\sum_{e=1}^{p}\left[k_{e}\right] \alpha_{e}} \\
& {[\Delta m]=\sum_{e=1}^{p}\left[\Delta m_{e}\right]=\sum_{e=1}^{p}\left[m_{e}\right] \alpha_{e}} \\
& {[\Delta S]=\sum_{e=1}^{p}\left[\Delta S_{e}\right]=\sum_{e=1}^{p}\left[S_{e}\right] \alpha_{e}}
\end{aligned}
$$


Several $\alpha_{e}$ s may refer to the same element but different properties such as bending, torsion, and stretching. The unknowns in the process of defining S2 from its specifications and $\mathrm{S} 1$ are the fractional changes $\alpha_{e}$. When the $\alpha_{e} s$ are defined it is ensured that element connectivity in the FE model is preserved and S2 represents a real structure.

\subsubsection{Step 4}

The differences in structural response between states SI and $\mathbf{S} 2$ are expressed implicitly in terms of the $\alpha_{e}$ s by the general perturbation equations. For modal dynamics we have:

$$
\begin{gathered}
\sum_{e=1}^{p}\left(\left\{\psi^{\prime}\right\}_{i}^{\mathrm{T}}\left[k_{e}\right]\left\{\psi^{\prime}\right\}_{i}-\omega_{i}^{\prime 2}\left\{\psi^{\prime}\right\}_{i}^{\mathrm{T}}\left[m_{e}\right]\left\{\psi^{\prime}\right\}_{i}\right) \alpha_{e} \\
=\omega_{i}^{\prime 2}\left\{\psi^{\prime}\right\}_{i}^{\mathrm{T}}[m]\left\{\psi^{\prime}\right\}_{i}-\left\{\psi^{\prime}\right\}_{i}^{\mathrm{T}}[k]\left\{\psi^{\prime}\right\}_{i} \\
\sum_{e=1}^{p}\left\{\psi^{\prime}\right\}_{j}^{\mathrm{T}}\left[k_{e}\right]\left\{\psi^{\prime}\right\}_{i} \alpha_{e}=-\left\{\psi^{\prime}\right\}_{j}^{\mathrm{T}}[k]\left\{\psi^{\prime}\right\}_{i} \\
\sum_{e=1}^{p}\left\{\psi^{\prime}\right\}_{j}^{\mathrm{T}}\left[m_{e}\right]\left\{\psi^{\prime}\right\}_{i} \alpha_{e}=-\left\{\psi^{\prime}\right\}_{j}^{\mathrm{T}}[m]\left\{\psi^{\prime}\right\}_{i}
\end{gathered}
$$

for $i=1,2, \ldots, n, j=i+1, i+2, \ldots, n{ }^{1,2}$ Equation (21) represents the $n$ diagonal terms of the energy balance equation $\left[K^{\prime}\right]-\left[M^{\prime}\right]\left[\omega^{\prime 2}\right]=0$ for $S 2$; that is, the Rayleigh quotients for $\omega_{i}^{\prime 2}$. Equations (22) and (23) represent the orthogonality conditions of modes $\left\{\psi^{\prime}\right\}_{i}$ with respect to $\left[k^{\prime}\right]$ and $\left[m^{\prime}\right]$. Theoretically, orthogonality of modes with respect to one of $\left[k^{\prime}\right]$ or $\left[m^{\prime}\right]$ implies orthogonality with respect to the other. Numerically, however, both conditions must be forced if $\left\{\psi^{\prime}\right\}_{i}, i=1,2, \ldots, n$ are to represent modes of a real structure.

The general perturbation equations for static deflections are derived from the counterpart of eqn (2) for structure $\mathrm{S} 2$ based on the modal dynamic expansion of $\left\{u^{\prime}\right\}$ in terms of the unknown modes $\left\{\psi^{\prime}\right\}_{i}$, $i=1,2, \ldots, n$. Thus, inversion of matrix $\left[k^{\prime}\right]$ is avoided. Linearizing only the explicit dependence on the $\alpha_{e} s$, we have: ${ }^{1,16}$

$$
u_{i}^{\prime}=\sum_{m=1}^{n_{r}}\left(\frac{\phi_{i m}^{\prime} A_{m}}{B_{m}}\right)-\sum_{e=1}^{p}\left(\sum_{m=1}^{n_{r}} \frac{\phi_{i m}^{\prime} A_{m}}{B_{m}^{2}} C_{m e}\right) \alpha_{e}
$$

where:

$$
\begin{gathered}
A_{m}=\sum_{j=1}^{n}\left(\phi_{j m}^{\prime} f_{j}^{\prime}\right), \quad B_{m}=\left\{\psi^{\prime}\right\}_{m}^{\mathrm{T}}[k]\left\{\psi^{\prime}\right\}_{m}, \\
C_{m e}=\left\{\psi^{\prime}\right\}_{m}^{\mathbf{T}}\left[k_{e}\right]\left\{\psi^{\prime}\right\}
\end{gathered}
$$

The general perturbation equations for static stresses are derived in a similar manner: ${ }^{15}$

$$
\begin{aligned}
\{\Delta \sigma\}= & -\{\sigma\}+\left([S]+\sum_{e=1}^{p}\left[s_{e}\right] \alpha_{e}\right) \\
& \times\left[\sum_{m=1}^{n} \frac{\phi_{i m}^{\prime} A_{m}}{B_{m}}-\sum_{e=1}^{p}\left(\sum_{m=1}^{n} \frac{\phi_{i m}^{\prime} A_{m}}{B_{m}^{2}} C_{m e}\right) \alpha_{e}\right]
\end{aligned}
$$

For global buckling, the general perturbation equations are derived using the same method as in the case of the modal dynamics eigenvalue problem: ${ }^{15}$

$$
\begin{aligned}
& \sum_{e=1}^{p}\left\{\psi_{\mathrm{b}}^{\prime}\right\}_{i}^{\mathrm{T}}\left(\left[k_{c_{e}}\right]-P_{i}^{\prime}\left[k_{\sigma_{\sigma_{e}}}\right]\right)\left\{\psi_{\mathrm{b}}^{\prime}\right\}_{i} \alpha_{e} \\
& =\left\{\psi_{\mathrm{b}}^{\prime}\right\}_{i}^{\mathrm{T}}\left(P_{i}^{\prime}\left[k_{\sigma_{0}}\right]-\left[k_{\mathrm{c}}\right]\right)\left\{\psi_{\mathrm{b}}^{\prime}\right\}_{i} \\
& \sum_{e=1}^{p}\left\{\psi_{\mathrm{b}}^{\prime}\right\}_{j}^{\mathrm{T}}\left[k_{c_{e}}\right]\left\{\psi_{\mathrm{b}}^{\prime}\right\}_{i} \alpha_{e}=-\left\{\psi_{\mathrm{b}}^{\prime}\right\}_{j}^{\mathrm{T}}\left[k_{c}\right]\left\{\psi_{\mathrm{b}}^{\prime}\right\}_{i} \\
& \sum_{e=1}^{p}\left\{\psi_{\mathrm{b}}^{\prime}\right\}_{j}^{\mathrm{T}}\left[k_{\sigma_{\sigma_{e}}}\right]\left\{\psi_{\mathrm{b}}^{\prime}\right\}_{i} \alpha_{e}=-\left\{\psi_{\mathrm{b}}^{\prime}\right\}_{j}^{\mathrm{T}}\left[k_{\sigma_{0}}\right]\left\{\psi_{\mathrm{b}}^{\prime}\right\}_{i}
\end{aligned}
$$

for $i=1,2, \ldots, n, \quad j=i+1, \quad i+2, \ldots, n, \quad$ where $\left[k_{c}\right]=\left[k_{0}\right]-\left[k_{\sigma \mathrm{F}}\right], k_{\sigma \mathrm{F}}$ includes the body force, and $\left[k_{\sigma}\right]=-P_{i}\left[k_{\sigma 0}\right]-\left[k_{\sigma \mathrm{F}}\right]$.

\subsubsection{Step 5}

In this final step, the problem of finding state $\mathrm{S} 2$ based on its specifications and results of FEA for $S 1$ is formulated and solved for the $p$ unknown $\alpha_{e}$ s using the LEAP algorithm presented in the next section. The problem formulation is as follows:

$$
\text { minimize }\|\boldsymbol{\alpha}\|_{2} \in \mathscr{R}^{p}
$$

subject to $n_{\nu}$ natural frequency objectives $\omega_{i}^{\prime 2}, i=$ $1,2, \ldots, n_{w} ; n_{\phi}$ normal mode objectives $\phi_{k i}^{\prime}$, number of $(k, i)=n_{\phi} ; n_{u}$ static deflection objectives $u_{i}^{\prime}, i=$ $1,2, \ldots, n_{u} ; n_{\sigma}$ static stress objectives $\sigma_{i}^{\prime}, i=1,2 \ldots, n_{\sigma}$; $n_{\mathrm{b}}$ global buckling eigenvalues $P_{i}^{\prime}, i=1,2, \ldots, n_{\mathrm{b}} ; n_{o \mathrm{~b}}$ buckling mode objectives $\phi_{\mathrm{b}_{k t}}^{\prime}$, number of $(k, i)=n_{\oplus \mathrm{b}} ; 2 p$ lower and upper bounds on the redesign variables $\alpha_{e},-1<\alpha_{e}^{-} \leq \alpha_{e} \leq \alpha_{e}^{+}$, $e=1,2, \ldots, p ; n_{\mathrm{a}}$ admissibility constraints extracted from eqns (22) and (23), where $n_{\mathrm{a}}=$ $2 \Sigma_{i=1}^{n_{\omega}}\left(n_{\mathrm{r}}-i\right)=n_{\omega}\left[\left(2 n_{\mathrm{r}}-1\right)-n_{\omega}\right] ;$ and $n_{\mathrm{ab}}$ admissibility constraints extracted from eqns (27) and (28), where $n_{\mathrm{ab}}=2 \sum_{i=1}^{n_{\mathrm{b}}}\left(n_{\mathrm{r}}-i\right)=n_{\mathrm{b}}\left[\left(2 n_{\mathrm{r}}-1\right)-n_{\mathrm{b}}\right]$. All of the above redesign objectives are substituted in the appropriate general perturbation equations (21)-(28). Of the general perturbation equations (21), (24)-(26), those that are not used in the optimization formulation may be used to predict the unspecified performance particulars of the objective state S2. Accuracy of those predictions, however, it not as high as those of the redesign objectives. 
All the constraints of the above problem may result in an empty, nonempty, or countable feasible domain. In the first case, the redesign objectives cannot be achieved for the sclected set of redesign variables, in which case a minimum error solution in satisfaction of the redesign objectives is achieved by a generalized inverse algorithm. ${ }^{37.8 .21}$ In the second case, an optimum solution is achieved using an optimality criterion (29).

\subsection{Large admissible perturbation (LEAP) algorithm}

The redesign problem formulated by PAR in Section 2.2 can be solved by a LEAP algorithm. Many LEAP algorithms have been developed to solve a variety of two-state problems $s^{2,3,4,7,21}$ and have been documented in detail. Suffice to present here the basic steps and difficulties of the solution algorithm. The LEAP algorithm developed to solve the redesign problem is outlined in Fig. 2. It starts from the baseline structure (S1) and reaches incrementally the objective $\mathrm{S} 2$ by prediction and correction. In the prediction phase of the algorithm, the small perturbation method 6.10 .11 is used. The modal dynamics general perturbation equations are linearized. For that purpose, increments are limited to $7 \%$ differences between $\mathrm{S} 2$ specifications and the corresponding $\mathrm{S} 1$ properties. Predictions are small but inadmissible because admissibility conditions (22) and (23) are linearized. In the correction phase, perturbations

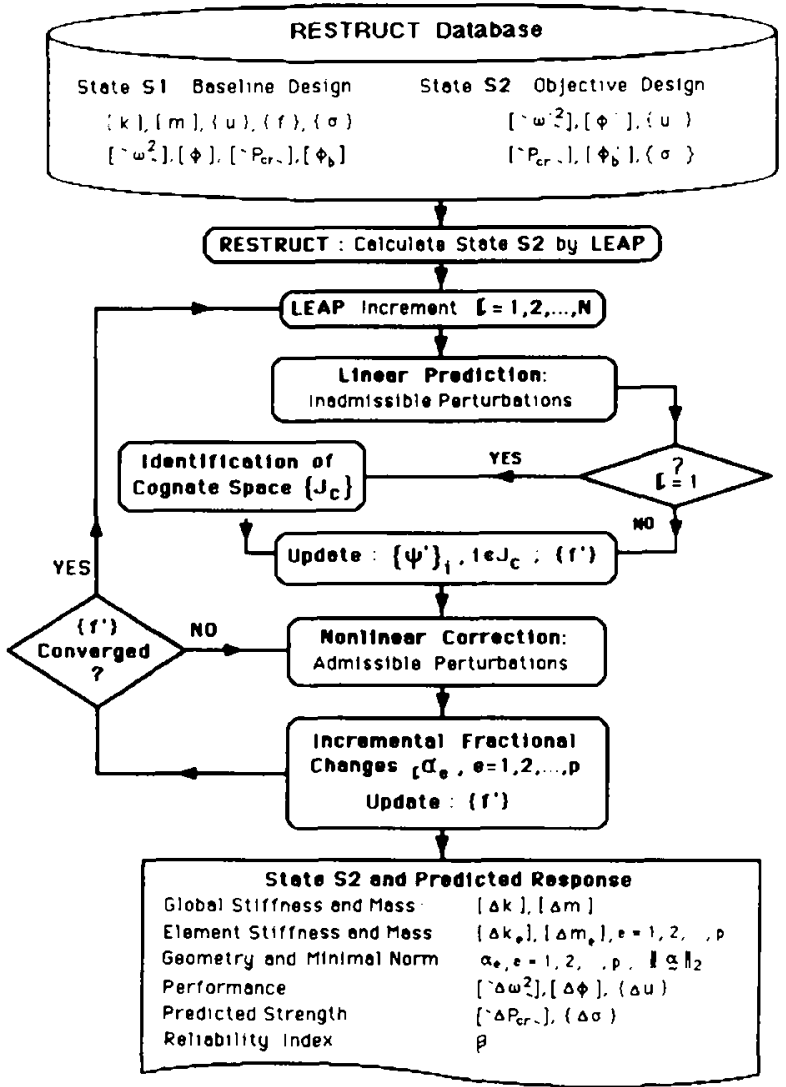

Fig. 2. Implementation of LEAP algorithm in code RESTRUCT. are corrected by satisfying the nonlinear general perturbation equations and are forced back into the admissible space by satisfying the nonlincar admissibility conditions. The total CPU time for redesign may be reduced by a factor occasionally as high as 4 when in the first increment the space of cognate modes is identified and thereafter all computations are performed in that space. Such is the case for torsional redesign ${ }^{7}$ of the offshore tower in Fig. 3. Torsional modes $^{3.18 .19}$ constitute one cognate subspace with very weak interaction with other modal subspaces such as those for bending and stretching.

In each increment, in both phases, the resulting problem may be underdetermined or overdetermined depending on the relation between the number $p$ of redesign variables $\alpha_{q^{\prime}}$, the number of equality constraints (S2 specifications) $n=-n_{u^{*}}+n_{0}+n_{u}+n_{r}+n_{\mathrm{b}}+n_{\text {ob }}$ ! $n_{\mathrm{a}}+N_{a b}$, and the $2 p$ bounds on the $a_{p},$. . When the problem is overdetermined, a minimum error solution in satisfaction of the $\mathrm{S} 2$ specifications is produced by a generalized inverse algorithm. When the problem is undetermined, it is solved by optimization using the minimum change criterion in eqn (29). To achieve this global objective, at each increment the objective in expression (30) is minimized. which takes into account the progress made in all previous increments towards the total minimum in eqn (29):

$$
\min \sum_{c-1}^{p}\left[\left(1+{ }_{l} \alpha_{e}\right) \prod_{q-1}^{l-1}\left(1+{ }_{q} \alpha_{c}\right)-1\right]^{2}
$$

The problem is solved by quadratic programming ${ }^{22}$ or sequential quadratic programming, ${ }^{23}$ depending on whether the expression for $[\Delta k]$ is linear as in eqn (18), or nonlinear as in the case of plate and shell redesign. In these cases, the plate or shell thickness is selected as redesign variable resulting in a cubic expression for $[\Delta k]$ in terms of the $\alpha_{e} s .[\Delta S]$ is always a nonlinear expression of the $\alpha_{e}$ s because $\left[S_{e}\right]$ depends on the distance of the point where the stress is computed from the neutral axis. The LEAP algorithm is implemented in code RESTRUCT. It is 27000 FORTRAN 77 commands and may serve as a postprocessor to any special or general purpose FE code. The authors presently use it to postprocess MSC: NASTRAN.V64 data on the secondary (UB) main frame computer (IBM-3090) of the University of Michigan.

The LEAP algorithm outlined above finds the optimum objective structure $\mathrm{S} 2$ without trial and error and with no additional FEAs. The $[k]$ matrix inversion required in static deflection and stress redesign is avoided by using modal expansions as shown in eqns (24) and (25). Thus, an accurate modal basis is mandatory even as $\mathbf{S} 2$ moves far away from S1. LEAP algorithms can surmount the following three difficulties as well. All general perturbation equations (which 


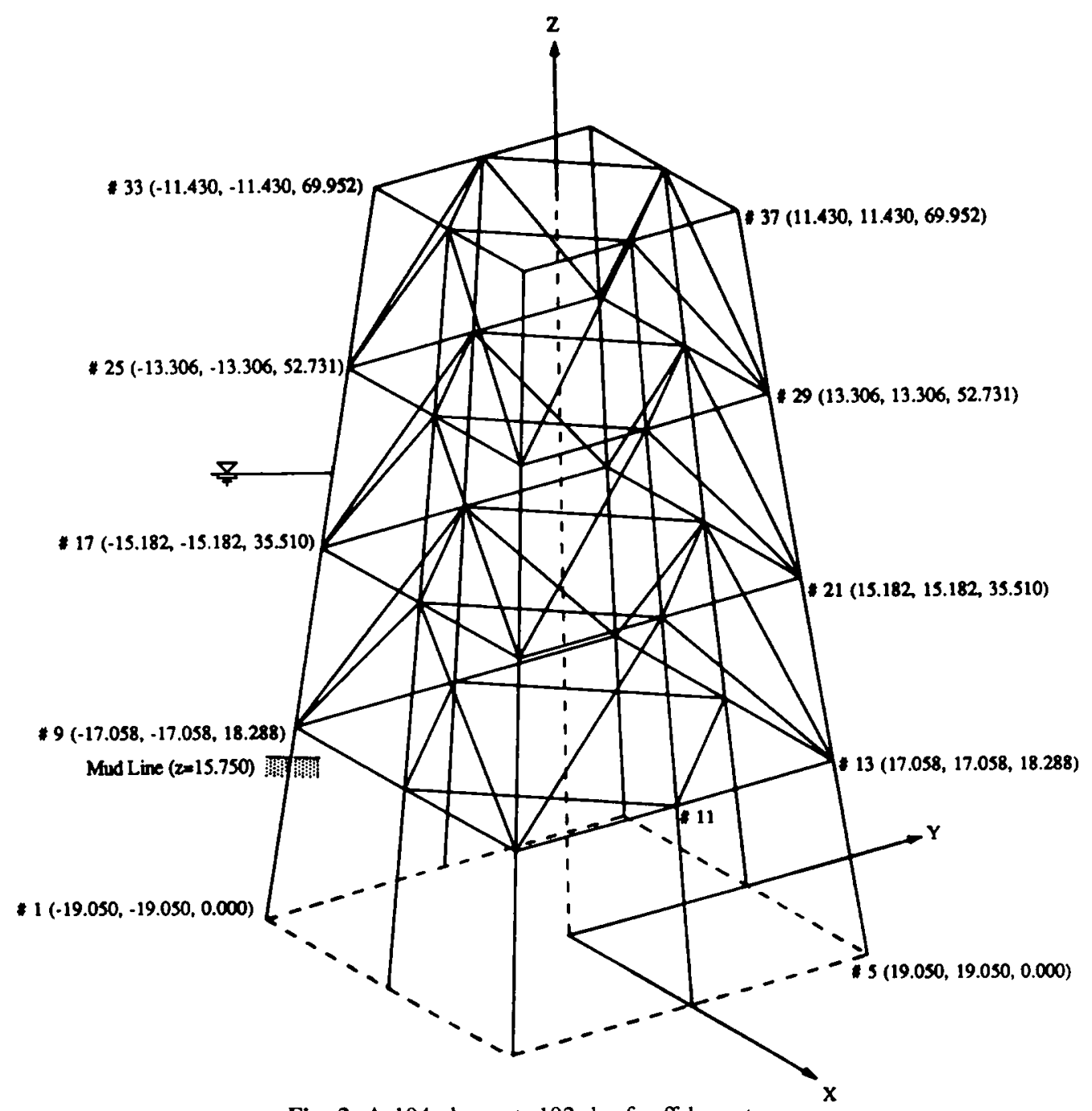

Fig. 3. A 104-element, 192-d.o.f. offshore tower.

become equality constraints in the optimization problem) are strongly nonlinear implicit expressions of the redesign variables $\alpha_{e}$. The static force vector $\left\{f^{\prime}\right\}$ may depend on the structure's geometry (e.g. hydrodynamic loads) and consequently change in the redesign process. Finally, the set of specifications provided for S2 are usually incomplete and only some d.o.f.s of specified modes are defined.

\section{NUMERICAL APPLICATIONS}

A total of 42 numerical applications are presented in this section on optimal redesign of four different structures. ${ }^{24-26}$ Results are summarized in Tables 1-4 and show the accuracy of code RESTRUCT for applications with number of redesign variables ranging from 8 to 21 ; natural frequency and mode shape redesign objectives changing by a factor ranging from 0.3 to $2 \cdot 0$; degrees of freedom ranging from 48 to 896 . For each redesign objective, Tables $1-4$ show the objective value, the value actually achieved as computed by reanalysis with MSC/ NASTRAN, and the corresponding relative error. CPU time and numbers of extracted modes $n_{\mathrm{r}}$, admissibility conditions $n_{\mathrm{a}}$, and redesign variables are also shown. The values of the redesign variables of the optimum solution are not shown. The optimal solution appears in the form of the optimal Eucledian norm of the $\alpha_{e} s$ in Tables 3 and 4; and in the form of the Hasover-Lind reliability index ${ }^{12}$ in Tables 1 and 2 .

\subsection{0-element 48-d.o.f. beam}

The clamped-hinged beam in Fig. 4 is subjected to a uniform load in the $\mathrm{Y}$-direction and a concentrated load applied at node 7 in the Z-direction. $\omega_{1}=183.092 \mathrm{rad} / \mathrm{s}$, the horizontal and vertical deflections at node 7 are $v_{7}=12.151 \mathrm{~mm}$ and $w_{7}=17.733 \mathrm{~mm}$ as computed by MSC/NASTRAN. Redesign variables and structural groups are shown in Table 5. The accuracy of the redesign process is shown in Table 1 for one, two or three simultaneous redesign objectives. The problem of reliability analysis is studied assuming randomness in geometric properties, $A$ (area), $I_{y}, I_{z}$ (moments of inertia), and material properties $E$ (Young's modulus) and $\rho$ (density). The fractional changes $\alpha_{e}$ are assumed 
Table 1. Redesign and reliability of clamped-hinged beam

\begin{tabular}{|c|c|c|c|c|c|c|c|c|c|c|c|c|c|c|}
\hline \multirow{2}{*}{$\begin{array}{c}\text { Case } \\
\text { no. }\end{array}$} & \multicolumn{3}{|c|}{ îن } & \multicolumn{3}{|c|}{$\therefore 1$} & \multicolumn{3}{|c|}{$w \div / 1 \%$} & \multirow[t]{2}{*}{1} & \multirow{2}{*}{$\begin{array}{l}\text { CPI: } \\
\text { ims: }\end{array}$} & \multirow[t]{2}{*}{$n_{1}$} & \multirow[t]{2}{*}{$n_{1}$} & \multirow[t]{2}{*}{$p$} \\
\hline & $\mathrm{FS}^{a}$ & Reanalysis & Error $(\%)$ & $\mathrm{FS}^{a}$ & Reanalysis & Error $(\%)$ & $\mathrm{FS}^{a}$ & Reanalysis & $\operatorname{Error}(\%)$ & & & & & \\
\hline 1 & 0.4588 & 0.4578 & -0.205 & - & & & & & & $2 \cdot 767$ & 31050 & 9 & $x$ & 14 \\
\hline 2 & & & & $2 \cdot(0358$ & $2 \cdot 0440$ & 0.405 & - & & & $3 \cdot 37$ & $56 \cdot 620$ & 10 & 12 & 14 \\
\hline 3 & & - & -- & - & & $\ldots-$ & $2 \cdot 0358$ & 2.0458 & 0.489 & $2 \cdot 718$ & 48378 & 9 & 8 & 14 \\
\hline 4 & 0.4588 & 0.4570 & -0.401 & $2 \cdot 0358$ & $2 \cdot 1124$ & $3 \cdot 762$ & & & & $4 \cdot 56$ & 75520 & 9 & 12 & 21 \\
\hline 5 & 0.4588 & 0.4554 & -0.736 & -- & & & $2 \cdot 0358$ & 2.0568 & 1.033 & $2 \cdot 713$ & 68486 & 11 & 10 & 14 \\
\hline 6 & - & & & 2.0358 & $2 \cdot 1125$ & $3 \cdot 769$ & 2.0358 & 2.0701 & & 3.884 & 90435 & 9 & 9 & 14 \\
\hline 7 & 0.4588 & 0.4545 & -0.931 & $2 \cdot 0358$ & $2 \cdot 1893$ & $7 \cdot 542$ & $2 \cdot 0358$ & 2.0737 & $1 \cdot 863$ & $4 \cdot 246$ & 105928 & 10 & 12 & 21 \\
\hline 11 & $0 \cdot 3$ & 0.2892 & $-3 \cdot 586$ & - & & & & & & 3.608 & & 11 & 10 & 14 \\
\hline 12 & & - & - & $3 \cdot 0$ & 3.0122 & 0.407 & & &.- & 4.418 & 80156 & 10 & 12 & 14 \\
\hline 13 & & - & $\ldots .$. & & & & $3 \cdot 0$ & 3.2152 & $7 \cdot 173$ & $3 \cdot 363$ & 108912 & 11 & 12 & 14 \\
\hline 14 & $0 \cdot 3$ & 0.2959 & $-1 \cdot 379$ & $3 \cdot 0$ & $3 \cdot 1554$ & $5 \cdot 179$ & - & - & & $6 \cdot 297$ & 116.314 & $y$ & 12 & 21 \\
\hline 15 & $0 \cdot 3$ & 0.2841 & $-5 \cdot 271$ &.-- & & & $3 \cdot 0$ & $3 \cdot 0997$ & $3 \cdot 325$ & 3.954 & 99915 & 11 & 10) & 14 \\
\hline 16 & --.. & & & $3 \cdot 0$ & $3 \cdot 2042$ & 6.801 & $3 \cdot 0$ & $3 \cdot 2969$ & $9 \cdot 898$ & $5 \cdot 040$ & 101394 & 7 & 5 & 14 \\
\hline 17 & $0 \cdot 3$ & $0 \cdot 2940$ & $.2 \cdot 002$ & $3 \cdot 0$ & $3 \cdot 3282$ & 10.942 & $3 \cdot 0$ & $3 \cdot 1003$ & $3 \cdot 342$ & $5 \cdot 528$ & 167822 & 10 & 12 & 21 \\
\hline
\end{tabular}

Cases $4,7,13,15$ and 17 are solved by the generalized inverse algorithm.

"FS, Failure state

Table 2. Redesign and reliability of offshore tower

\begin{tabular}{|c|c|c|c|c|c|c|c|c|c|c|}
\hline \multirow{2}{*}{$\begin{array}{c}\text { Case } \\
\text { no. }\end{array}$} & \multicolumn{3}{|c|}{$\omega_{1}^{\prime 2} / \omega_{1}^{2}$} & \multicolumn{3}{|c|}{$\omega_{3}^{\prime 2} / \omega_{3}^{2}$} & \multirow[t]{2}{*}{3} & \multirow{2}{*}{$\begin{array}{l}\text { CPU } \\
\text { (ms) }\end{array}$} & \multirow[t]{2}{*}{$n_{\mathrm{r}}$} & \multirow[t]{2}{*}{$n_{\mathrm{a}}$} \\
\hline & $\mathrm{FS}^{a}$ & Reanalysis & Error $(\%)$ & $\mathrm{FS}^{a}$ & Reanalysis & Error $(\%)$ & & & & \\
\hline 1 & 0.6598 & 0.6531 & 1.018 & 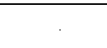 & - & $\cdots$ & $2 \cdot 104$ & 973814 & 18 & 8 \\
\hline 2 & ... & $\ldots$ & & 0.6598 & 0.6530 & -1.030 & 1.950 & 925711 & 19 & 8 \\
\hline 3 & 0.6598 & 0.6547 & $-0 \cdot 786$ & 0.6598 & 0.6541 & -0.871 & 3.061 & 985832 & 18 & 8 \\
\hline 11 & 0.5000 & 0.4871 & $.2 \cdot 572$ & ... & - & $\ldots$ & $2 \cdot 834$ & 1589439 & 18 & 8 \\
\hline 12 &.- & - & - & 0.5000 & 0.4844 & $-3 \cdot 112$ & 4.635 & 1529708 & 19 & 8 \\
\hline 13 & 0.5000 & 0.4895 & $-2 \cdot 100$ & 0.5000 & 0.4877 & $-2 \cdot 462$ & $3 \cdot 701$ & 1617425 & 18 & 8 \\
\hline
\end{tabular}

$p=12$; cases 12 and 13 are solved by the generalized inverse algorithm.

${ }^{a}$ FS, Failure state.

Table 3. Redesign of 64-element 216-d.o.f. plate

\begin{tabular}{|c|c|c|c|c|c|c|c|c|c|c|c|}
\hline \multirow{2}{*}{$\begin{array}{c}\text { Case } \\
\text { no. }\end{array}$} & \multicolumn{3}{|c|}{$u_{1}^{\prime 2} / \omega_{1}^{2}$} & \multicolumn{3}{|c|}{$\omega_{3}^{\prime 2} / \omega_{3}^{2}$} & \multicolumn{3}{|c|}{$u_{\max }^{\prime} / u_{\max }$} & \multirow[t]{2}{*}{$\sum \alpha_{e}^{2}$} & \multirow{2}{*}{$\begin{array}{c}\text { CPU } \\
(s)\end{array}$} \\
\hline & Goal & Reanalysis & Error $(\%)$ & Goal & Reanalysis & Error $(\%)$ & Goal & Reanalysis & Error $(\%)$ & & \\
\hline 1 & 1.2867 & 1.2844 & -0.177 & - & - & - & & & . & 0.0267 & 263 \\
\hline 2 & $2 \cdot 0000$ & 1.9818 & -0.909 & - & & & & - & $\ldots$ & 0.2354 & 713 \\
\hline 3 & & & & .. & & & 0.7579 & 0.7633 & 0.718 & 0.0358 & 420 \\
\hline 4 & $\ldots$ & & $--\cdot$ & 一 & - & & $0 \cdot 5000$ & 0.5069 & $1 \cdot 374$ & 0.2794 & 1044 \\
\hline 5 & $1 \cdot 2867$ & $1 \cdot 2842$ & $-0 \cdot 195$ & & -- & - & 0.7772 & 0.7818 & 0.594 & 0.0295 & 440 \\
\hline 6 & $2 \cdot 0000$ & 1.9801 & -0.997 & - & - &..- & 0.5000 & 0.5064 & $1 \cdot 289$ & 0.2816 & 1199 \\
\hline 7 & $1 \cdot 2867$ & $1 \cdot 2848$ & $-0 \cdot 144$ & $1 \cdot 1589$ & $1 \cdot 1572$ & $-0 \cdot 140$ & - & -- & -- & 0.0275 & 381 \\
\hline 8 & $2 \cdot 0000$ & 1.9848 & $-0 \cdot 760$ & $1 \cdot 5000$ & 1.4875 & -0.831 & & & & $0 \cdot 2407$ & 1037 \\
\hline 9 & 1.2867 & $1 \cdot 2840$ & $-0 \cdot 204$ & $1 \cdot 2867$ & $1 \cdot 2788$ & -0.621 & 0.7772 & 0.7821 & 0.631 & $0 \cdot(0549$ & 562 \\
\hline 10 & $2 \cdot 0000$ & 1.9747 & $-1 \cdot 264$ & $2 \cdot 0000$ & 1.9198 &. $.4 \cdot 011$ & 0.5000 & 0.5077 & 1.531 & 0.4378 & 1532 \\
\hline 11 & $1 \cdot 3195$ & $1 \cdot 3157$ & $-0 \cdot 287$ & $1 \cdot 3195$ & $1 \cdot 3103$ & -0.697 & 0.6598 & 0.6649 & 0.787 & 0.1561 & 833 \\
\hline 12 & $2 \cdot 0000$ & 1.9721 & $-1 \cdot 395$ & $2 \cdot 0000$ & 1.9341 & $-3 \cdot 397$ & 0.3536 & 0.3600 & 1.831 & $1 \cdot 2394$ & 2072 \\
\hline 13 & $1 \cdot 2867$ & $1 \cdot 2844$ & -0.173 & $1 \cdot 1589$ & $1 \cdot 1574$ & $-0 \cdot 125$ & 0.7772 & 0.7817 & 0.577 & 0.0297 & 562 \\
\hline 14 & $2 \cdot 0000$ & 1.9806 & -0.971 & $1 \cdot 5000$ & 1.4941 & -0.395 & 0.5000 & 0.5063 & 1.259 & 0.2817 & 1528 \\
\hline 15 & $1 \cdot 3195$ & $1 \cdot 3093$ & -0.774 & $1 \cdot 1761$ & $1 \cdot 1691$ & -0.591 & 0.6598 & 0.6678 & $1 \cdot 224$ & 0.1618 & 832 \\
\hline 16 & $2 \cdot 0000$ & 1.9104 & -4.479 & $1 \cdot 5000$ & 1.4408 & -3.950 & 0.3536 & 0.3710 & 4.945 & $1 \cdot 3025$ & 2065 \\
\hline
\end{tabular}

In all cases: $n_{\mathrm{r}}=7, n_{\mathrm{a}}=5, p=8$. 
Table 4. Redesign of simply supported cylindrical shell

\begin{tabular}{|c|c|c|c|c|c|c|c|c|c|c|c|}
\hline \multirow{2}{*}{$\begin{array}{c}\text { Case } \\
\text { no. }\end{array}$} & \multicolumn{3}{|c|}{$\omega_{1}^{\prime 2} / \omega_{1}^{2}$} & \multicolumn{3}{|c|}{$\omega_{2}^{\prime 2} / \omega_{2}^{2}$} & \multicolumn{3}{|c|}{$u_{x}^{\prime} / u_{x}$} & \multirow[t]{2}{*}{$\Sigma \alpha_{e}^{2}$} & \multirow{2}{*}{$\begin{array}{c}\text { CPU } \\
(\mathrm{s})\end{array}$} \\
\hline & Goal & Reanalysis & Error $(\%)$ & Goal & Reanalysis & Error $(\%)$ & Goal & Reanalysis & Error $(\%)$ & & \\
\hline 1 & $1 \cdot 3307$ & $1 \cdot 3184$ & -0.74 & - & - & $\ldots$ & - & - & - & 0.766 & 571 \\
\hline 2 & $1 \cdot 5700$ & $1 \cdot 5400$ & -1.95 & - & $\ldots$ & - & - & - & - & $1 \cdot 330$ & 715 \\
\hline 3 & 1.9162 & $1 \cdot 7610$ & $-3 \cdot 90$ & - & - & - & - & & -- & 1.576 & 1129 \\
\hline 4 & 1.9162 & 1.7610 & -3.90 & 1.6700 & $1 \cdot 5000$ & $-9 \cdot 000$ & - & - & & 1.805 & 2241 \\
\hline 5 & $1 \cdot 331$ & $1 \cdot 3200$ & -0.74 & - & - & - & 0.6480 & 0.6610 & $2 \cdot 000$ & 0.579 & 940 \\
\hline 6 & 1.9171 & 1.7610 & -3.90 & - & - &.-- & 0.648 & 0.646 & 0.00 & 1.945 & 2352 \\
\hline
\end{tabular}

In all cases: $n_{\mathrm{r}}=5, n_{\mathrm{a}}=5$.

to be independent normal random variables of zero mean. Standard deviations are selected as $\sigma_{\alpha_{E I}}=0.40$ for bending rigidities $E I_{y}$ and $E I_{z}$, and $\sigma_{\alpha_{\rho A}}=0.30$ for mass per unit length $\rho A$. In order to compute the probability of failure to first (FORM) or second (SORM) order, ${ }^{13}$ computation of individual and joint design points and the corresponding Hasover-Lind reliability index $\beta$ is required as shown in Fig. 5 . Computation of $\beta$ is achieved by transforming the $\alpha_{p}$ s to independent standard normal random variables through the Rosenblatt transformation. ${ }^{27}$ These numerical applications as well as those following on the offshore tower show that large admissible perturbation methods can introduce sophisticated structural analysis in reliability without simplifying the structural model and without repeated FEAs. ${ }^{5}$

\subsection{4-element 192-d.o.f. offshore tower}

The offshore tower shown in Fig. 3 is $69.95 \mathrm{~m}$ high and operates in $45.72 \mathrm{~m}$ water depth. The tower at the base is square with a $38.10 \mathrm{~m}$ side and tapers linearly to $22.86 \mathrm{~m}$ at the deck. The FE model of the tower is composed of 104 circular tubular beam elements and has 192 d.o.f.s. Loading on the tower is due to the following. (i) A 240 tonne deck load which is applied to the structure as uniformly distributed load at the deck nodal points. (ii) Wave hydrodynamic forces calculated for a design wave of $182.88 \mathrm{~m}$ length and $6.10 \mathrm{~m}$ height using Morison's equation; the wave propagates in the $X$-direction. (iii) Wind generated water current in the $X$-direction with linear velocity profile of $1.03 \mathrm{~m} / \mathrm{s}$ at the mean free surface waterline and zero at the sea bed. $\omega_{1}=\omega_{2}=4.695 \mathrm{rad} / \mathrm{s}$ for the first bending modes in the $X Z$ and the $Y Z$ planes. $\omega_{3}=5.353 \mathrm{rad} / \mathrm{s}$ for the first torsion mode with respect to axis $Z$. Redesign variables and structural groups are shown in Table 6.

Failure states are defined by deterioration factors in the first and third eigenvalues of 1.54 and 2.00. Geometric and material properties are random. The fractional changes $\alpha_{e}$ s, shown in Table 3, are assumed to be independent normal random variables with zero mean. Standard deviations are selected as $\sigma_{\alpha_{E I}}=0.40$ for bending rigidity $E I$ and $\sigma_{x_{p 4}}=0.30$ for mass per unit
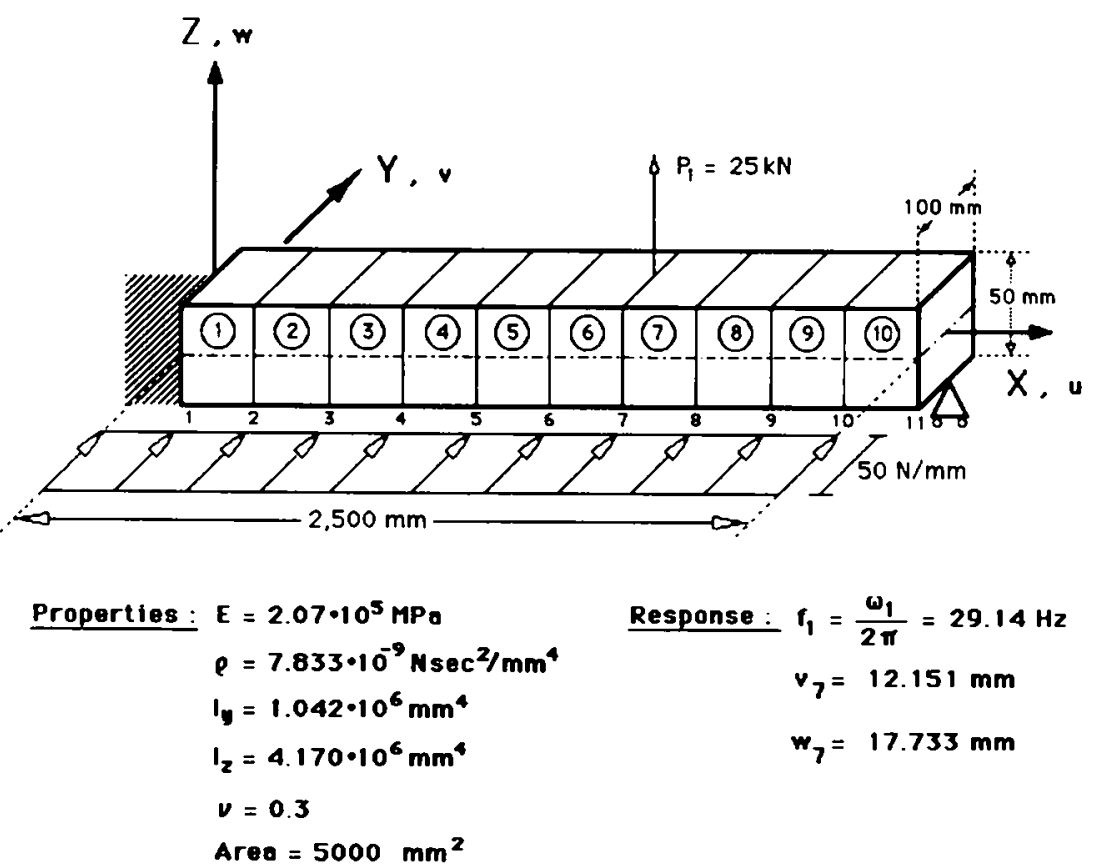

Fig. 4. A 10-element, 48-d.o.f. clamped-hinged beam. 


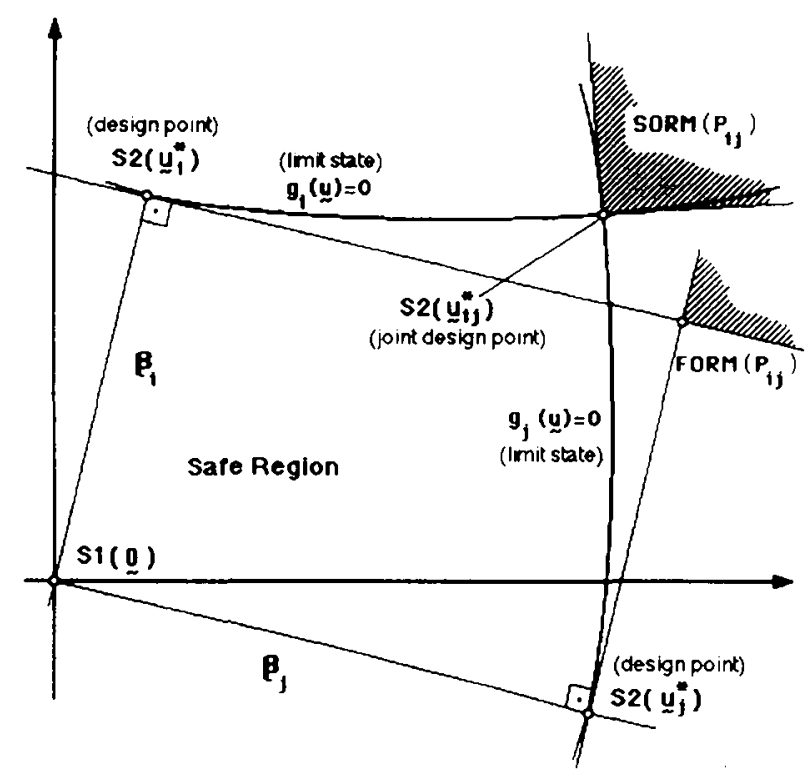

Fig. 5. First and second order methods for reliability computations.

length $\rho A$. Design points are computed again by postprocessing FE analysis results for the baseline design only. It should be noted that in Tables 2 and 5 the computed $\beta$ is high in some applications (cases 14 and 17) because the external load is deterministic and limit states were pushed as far away from the baseline design as possible in order to demonstrate the accuracy and limitations of code RESTRUCT. Actually, in cases 14 and 17 the limit point is a double and triple design point respectively. Such failure is expected to be of low probability.

\subsection{4-element 216-d.o.f. plate}

The clamped-free-free-free plate in Fig. 6 is subjected to a uniform load $p$ and has the dimensions and properties shown in the figure. Its response is computed by MSC; NASTRAN and redesign is performed by RESTRUCT. The incremental optimization problem is nonlinear and solved by sequential quadratic programming ${ }^{23}$ because
Table 5. 10-element, 48-d.o.f. clamped-hinged beam: structural groups and redesign variables

\begin{tabular}{|c|c|c|}
\hline $\begin{array}{l}\text { Structural } \\
\text { group no. }\end{array}$ & Redesign variables, $\alpha_{r} \therefore p-21$ & $\begin{array}{c}\text { Filemen } \\
\text { nos }\end{array}$ \\
\hline 1 & $\alpha_{1}\left(\alpha_{t I_{v}}\right) \cdot \alpha_{2}\left(\alpha_{Z_{1}}\right) \cdot \alpha_{3}\left(\alpha_{\varphi, 4}\right)$ & 1.2 \\
\hline 2 & $\alpha_{4}\left(\alpha_{E I_{r}}\right), \alpha_{5}\left(\alpha_{E: 1}\right), \alpha_{6}\left(\alpha_{\rho-4}\right)$ & 3.4 \\
\hline 3 & $\alpha=\left(\alpha_{E I}\right), r_{g}\left(\alpha_{E I_{t}}\right), \alpha_{y}\left(\alpha_{p, A}\right)$ & 5 \\
\hline 4 & $\alpha_{110}\left(\alpha_{E I}\right), \alpha_{11}\left(\alpha_{E I}\right), \alpha_{12}\left(\alpha_{p, 4}\right)$ & 6 \\
\hline 5 & $\alpha_{13}\left(\alpha_{Y_{1} I_{1}}\right), \alpha_{14}\left(\alpha_{H I}\right), \alpha_{15}\left(\alpha_{\mu A}\right)$ & $?$ \\
\hline 6 & $\alpha_{16}\left(\alpha_{Y I_{1}}\right), \alpha_{17}\left(\alpha_{k 1}\right), \alpha_{18}\left(\alpha_{p H A}\right)$ & 8 \\
\hline 7 & $\alpha_{19}\left(\alpha_{t I I}\right) \cdot \alpha_{20}\left(\alpha_{t I I}\right) \cdot \alpha_{21}\left(\alpha_{p-A}\right)$ & 9.10 \\
\hline
\end{tabular}

$[\Delta k]$ is a cubic expression of the $\alpha_{e} s$ which represent fractional changes of the plate thickness. ${ }^{24.28}$ The plate is subdivided into eight structural groups each containing eight finite elements. Results of redesign are summarized in Table 3 and show very high accuracy even for changes by a factor of 2 in eigenvalues and maximum deflection.

\subsection{4-element 896-d.o.f. cylindrical shell}

The simply-supported shell shown in Fig. 7 is subjected to hydrostatic pressure load $p$ due to $286 \mathrm{~m}$ submergence in salt water. ${ }^{29}$ Dimensions ${ }^{30}$ and properties are also shown in the figure. Its modal dynamic and static deflection response r.,32 $^{31}$ computed by $\mathrm{MSC}_{/}$NASTRAN. The optimization problem in each increment is nonlinear and solved by sequential quadratic programming. ${ }^{23}$ The cylindrical shell is subdivided into five structural groups and even though symmetry is not forced by linking symmetric groups ( 1 and 5. 2 and 4) as was done in the plate redesign problem, symmetry was not lost in the redesign process. Results of code RESTRUCT are summarized in Table 4 and show good accuracy even for changes by a factor of 2 in eigenvalues and deflection.

In all of the above applications, the LEAP algorithm in RESTRUCT can be pushed further by taking additional incremental steps if higher errors are considered acceptable. For higher accuracy, however. one more FE analysis may be used after about 10 increments.

Table 6. 104-element, 192-d.o.f. offshore tower: structural groups, redesign variables, and dimensions

\begin{tabular}{|c|c|c|c|c|c|}
\hline $\begin{array}{l}\text { Structural } \\
\text { group }\end{array}$ & $\begin{array}{c}\text { Redesign } \\
\text { variables } \alpha_{\varphi}\end{array}$ & Description & $\begin{array}{l}D_{0} \\
(\mathrm{~m})\end{array}$ & $\begin{array}{c}D_{i} \\
(\mathrm{~m})\end{array}$ & $\begin{array}{c}\text { Element } \\
\text { nos }\end{array}$ \\
\hline 1 & $\begin{array}{l}\alpha_{1}\left(\alpha_{F I}\right) \\
\alpha_{2}\left(\alpha_{p, 4}\right)\end{array}$ & $\begin{array}{c}\text { Legs below first } \\
\text { bracing }\end{array}$ & 0.762 & 0.737 & 8 \\
\hline 2 & $\begin{array}{l}\alpha_{3}\left(\alpha_{E 1}\right) \\
\alpha_{4}\left(\alpha_{p A}\right)\end{array}$ & $\begin{array}{l}\text { Legs between first } \\
\text { and second bracing }\end{array}$ & 0.610 & 0.584 & 8 \\
\hline 3 & $\begin{array}{l}\alpha_{5}\left(\alpha_{E I}\right) \\
\alpha_{6}\left(\alpha_{\rho A}\right)\end{array}$ & $\begin{array}{c}\text { Legs above second } \\
\text { bracing }\end{array}$ & 0.610 & 0.584 & 16 \\
\hline 4 & $\begin{array}{l}\alpha_{7}\left(\alpha_{A I}\right) \\
\alpha_{8}\left(\alpha_{0.4}\right)\end{array}$ & $\begin{array}{c}\text { Horizontal } \\
\text { bracing }\end{array}$ & 0.483 & 0.464 & 32 \\
\hline 5 & $\begin{array}{l}\alpha_{9}\left(\alpha_{E, I}\right) \\
\alpha_{10}\left(\alpha_{p, 4}\right)\end{array}$ & $\begin{array}{c}\text { Horizontal } \\
\text { cross-bracing }\end{array}$ & 0.508 & 0.489 & 16 \\
\hline 6 & $\begin{array}{l}\alpha_{11}\left(\alpha_{E I}\right) \\
\alpha_{12}\left(\alpha_{\rho A}\right)\end{array}$ & $\begin{array}{c}\text { Vertical } \\
\text { cross-bracing }\end{array}$ & 0.610 & 0.591 & 24 \\
\hline
\end{tabular}




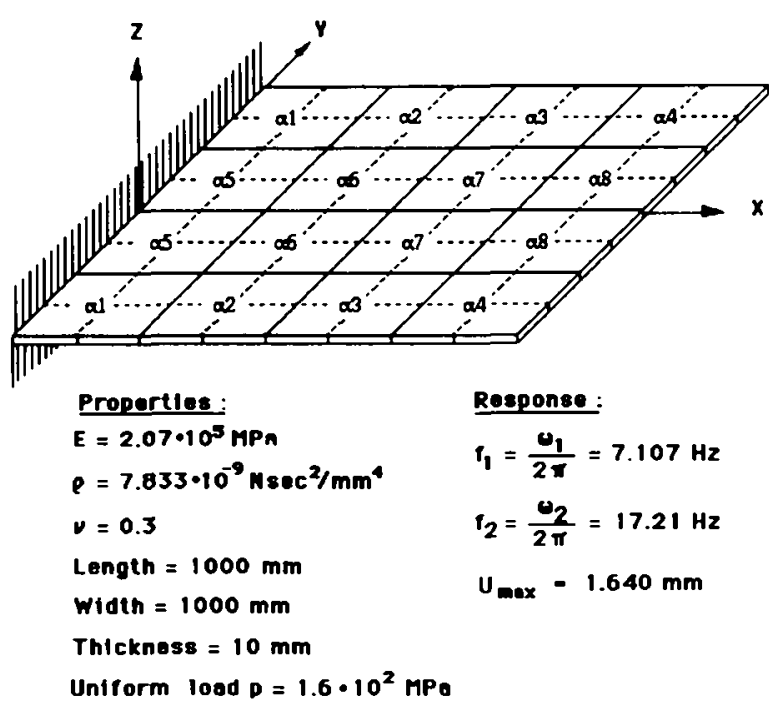

Fig. 6. A 64-element, 216-d.o.f. plate.

\section{CONCLUDING REMARKS}

Several two-state problems in structural analysis, design, and redesign can be formulated by PAR and solved by a LEAP algorithm. The objective structural design is found incrementally without trial and error or repeated FEAs for differences in response from the baseline design of the order of $100 \%$ or more. In structural reliability, PAR provides an attractive alternative to stochastic finite elements and structural systems approach.

Computer code RESTRUCT, which implements the large admissible perturbations methodology, is being developed since 1982, has been tested thoroughly and has generated confidence in its potential to solve twostate problems. Several theoretical and numerical developments are under way. New types of finite

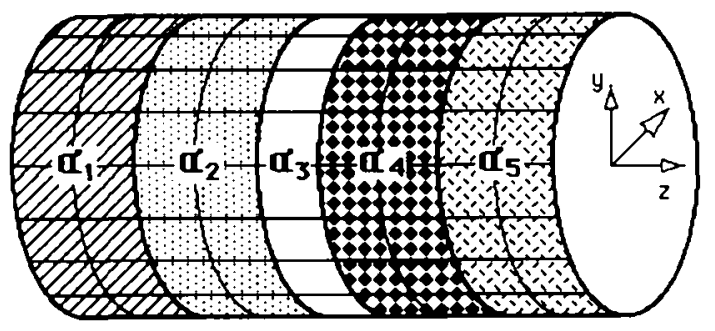

Simply Supported Cylindrical Shell

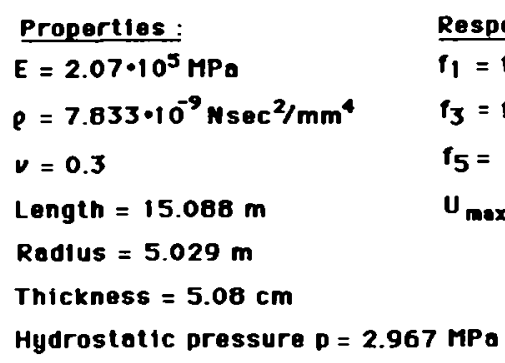

Fig. 7. A 144-element, 896-d.o.f. cylindrical shell. elements are being introduced; new structures are being redesigned, such as stiffened plates and shells; new twostate problems are studied, e.g. submarine acoustic noise reduction, redesign for buckling objectives, redesign for stress objectives; a perturbation approach to reliability analysis and design is being developed; larger scale structures are being redesigned by postprocessing FEA results by MSC/NASTRAN.V66 which has superelement capability. For that purpose, a supercomputer version of RESTRUCT running on the San Diego supercomputer has been developed.

\section{ACKNOWLEDGMENTS}

Research support provided by the Office of Naval Research through Grant No. DOD-G-N00014-90-J4081 is gratefully acknowledged.

\section{REFERENCES}

1. Bernitsas, M.M., Kang, B.S. \& Tawekal, R., RESTRUCT Version 3.0: A Program for REdesign of STRUCTures, Publication no. 312, Department of Naval Architecture and Marine Engineering, The University of Michigan, Ann Arbor, MI, Oct. 1989.

2. Tawekal, R.L. \& Bernitsas, M.M., Finite element model correlation for offshore structures. In Proc. 10th Int. OMAE Conf., Norway, June 1991, pp. 317-26. J. of OMAE (in press).

3. Bernitsas, M.M. \& Kang, B.S., Admissible large perturbations in structural redesign. AIAA Journal, 29 (1991) 104-13.

4. Kang, B.S., Beyko, E. \& Bernitsas, M.M., Invariant and consistent redundancy by large admissible perturbations. J. Marine Structures, 5(1) (1992)

5. Beyko, E., Development of a large admissible perturbation methodology for reliability of large scale structures. PhD dissertation, Department of Naval Architecture and Marine Engineering, The University of Michigan, Ann Arbor, MI, June 1992.

6. Sandström, R.E. \& Anderson, W.J., Modal perturbation methods for marine structures. SNAME Trans., 90 (1982) 4154

7. Bernitsas, M.M. \& Tawekal, R.L., Structural model correlation using large admissible perturbations in cognate space. AIAA Journal, 29(12) (1991)

8. Hoff, C.J. \& Bernitsas, M.M., Dynamic redesign of marine structures. J. Ship Res., 29(4) (1985) 285-95.

9. Hoff, C.J., Bernitsas, M.M., Sandström, R.E. \& Anderson, W.J., Nonlinear incremental inverse perturbation method for structural redesign. AIAA Journal, 22(9) (1984) 1304 9.

10. Stetson, K.A., Perturbation method of structural design relevant to Holographic vibration analysis. AIAA Journal, 13 (1975) 457-9.

11. Stetson, K.A. \& Harrison, I.R., Redesign of structural vibration modes by finite-element inverse perturbation. ASME Trans., J. Engg for Power, 103(2) (1981) 319-25.

12. Hasofer, A.M. \& Lind, N.C., Exact and invariant secondmoment code format. $J$. Engg Mech. Div., ASCE, 100 (1974) 111-21 
13. Madsen, H.O., Krenk. S. \& Lind, N.C.. Methods of Structural Safety. Prentice-Hall, Englewood Cliffs. NJ. 1986.

14. Beyko, E. \& Bernitsas, M.M., Reliability of large scale structures by large admissible perturbations. In Proc. 11 th OMAE Conf., Calgary, Canada, June 1992.

15. De. R.S., Offshore structural system reliability: Wave-load modeling, system behavior, and analysis, Report No. RMS-6, Department of Civil Engincering. Stanford University, March 1990.

16. D'Oliveira, J.G. \& Zimmer, R.A., Redundancy considerations in the structural design of floating offshore platforms. In Proc. Design Inspection-Redundancy Symposium. Williamsburg. VA. Nov. 1983, pp. 13.1 13.31.

17. Nordal, H., Cornell. C.A. \& Karamchandani, A.. A structural system reliability case study of an eight-leg steel jacket offshore production platform. In Proc. Marine Structural Reliability Symp.. SNAME. Arlington, VA. 5 6 Oct. 1987. pp. 193--216

18. Thoft-Christensen, P. \& Murotsu, Y., Application of Structural Systems Reliability Theory, Springer-Verlag. Berlin. 1986.

19. Liu, P.-L. \& Der Kiureghian. A., Finite element reliability of two dimensional continua with geometrical nonlinearity. In Proc. 5th Int. Conf. on Structural Safety and Reliability. ICOSSAR 89, Aug. 1989. San Francisco. pp. $1089 \cdot 96$.

20. Vanmarcke, E., Shinozuka, M., Nakagiri, S., Schueller, G.I. \& Grigoriu, M., Random fields and stochastic finite elements. Structural Safety. 3 (1986) 14366

21. Kim, J.H. \& Bernitsas, M.M., Redesign of marine structures by perturbation. J. Marine Structures. 1 (1988) 13983

22. Gill, P.E., Murray. W., Saunders, M.A. \& Wright, M.H..
Liser's Guide for SOLQPSOL: A Forrran Package for Quadratic Programming. Department of Operations Rescarch. Stanford University, 1983

23. Gill, P.E.. Murray. W., Saunders, M.A.\& Wright, M.H. l'ser's Guide for SOLINPSOL: A Fortran Package for Nonlinear Programming. Department of Operations Research. Stanford University. 1983.

24. Prasad, B. \& Haftka, R.T.. Optimal structural design with plate finite elements. ASCE, J. Structural Div.. 105 (1979) 236782.

25. Haftka, R.T.. Gürdal, Z. \& Kamat. M.P.. Elements of Structural Optimization. (2nd revision ed). Kluwer Academic Publishers. 1990)

26. Yoshidao, N. \& Vanderplaats, G.N.. Structural optimization using beam elements. AlA.4 Journal. 26(4) (1988) 45462.

27. Hohenbichler, M.\& Rackwitı, R., Non-normal dependent vectors in structural safety. J. Engg Mech. Div., ASCE, 107 (1981) $1227 \quad 38$

28. Koski. J.. Silvennoinen, R. \& Lawo, M., Multicriterion plate optimization. In Structural Optimization, ed. G.I.N Rosvany \& B.L. Karihaloo. Proc. IUTAM Symp. on Structural Optimization. Melbourne, 9-13 Feb. 1988. pp. 159167

29. Ross, C.T. Pressure Vessels Linder External Pressure: Statics and Dynamics, Elsevier Applied Science, 1990.

30. Simitses, G.J. \& Aswani, M.. Minimum-weight design of stiffened cylinders under hydrostatic pressure. J. Ship Res. 21(4) (1977) $217 \quad 24$

31. Koga. T., Effects of boundary conditions on the free vibrations of circular cylindrical shells. AlA A Journal, 26 (1988) 138794

32. Leissa. A., Vibration of Shells. NASA SP-288. Washington, DC. 1973. 